Int. J. Dev. Biol. 55: 345-351

doi: $10.1387 / \mathrm{ijdb} .103212 \mathrm{rm}$

\title{
Evolution of angiogenesis
}

\author{
RAMÓN MUÑOZ-CHÁPULI* \\ Department of Animal Biology, Faculty of Science, University of Málaga, Málaga, Spain
}

\begin{abstract}
Endothelial cells, which are the main agents of the angiogenic process in vertebrates, are lacking in the vessels of invertebrates. These are limited by the basement membranes of epithelial or myoepithelial cells. This fact leads to the questions of how vessels grow in invertebrates and how vertebrate angiogenesis evolved. We herein review the knowledge available about vascular growth in invertebrates. The cases described include the ascidian Botryllus, the annelid Hirudo and the squid Idiosepius. All these processes of vascular growth in invertebrates show substantial differences with the vertebrate angiogenesis, although the signalling system mediated by VEGF and its receptor VEGFR seems to be involved in all cases. However, VEGF signalling is used by many processes of cell directional migration, and it cannot be considered as a hallmark of angiogenesis. We also describe the close similarity between the molecular control of the endothelial angiogenesis and the branching morphogenesis of the tracheal system of insects. In both cases, the process is regulated by hypoxia and activates a leading tip cell which inhibits responsiveness of the adjacent cells through a Delta/Notch signalling pathway. We suggest that endothelial angiogenesis in vertebrates arose through cooption of this hypoxia-sensing mechanism by replacing the FGF/ FGFR axis of insects by a VEGF/VEGFR-mediated system, and adding a second layer of control of the endothelial state (quiescent or activated) mediated by angiopoietins and Tie receptors. This evolutionarily new control mechanism of endothelial angiogenesis establishes an endothelial/ perivascular cell crosstalking which does not exist in invertebrates.
\end{abstract}

KEYWORDS: angiogenesis, evolution, endothelium, myoepithelial cell, VEGF, VEGFR

\section{Introduction}

Angiogenesis is the process of formation of new blood vessels from other pre-existent ones. Although fully equivalent from the etymological point of view, the term "vasculogenesis" is restricted to the developmental process by which vascular progenitors (angioblasts) assemble to form a new vessel. Thus, the formation of the primitive vascular pattern during vertebrate embryonic development occurs through vasculogenesis, while the vessels later spread throughout the body by a combined process of angiogenesis and vasculogenesis. In some parts of the body, like the limbs, vascular growth involves recruitment of local angioblasts that become incorporated to the vessel walls. In other organs lacking of angioblasts, like the neural tube, purely angiogenic ingrowth of vessels accounts for vascularization (Carmeliet, 2005; Semenza, 2007).

In adults, most endothelial cells are in a quiescent state and the vascular network is basically stable. However, adult angiogenesis is an important physiological process for tissue repair and remodelling, and it is tightly regulated by a balance between activating and inhibiting signals. In vertebrates, tissue hypoxia is the main signal triggering an angiogenic response, through stimulation of the vascular endothelial growth factor (VEGF)/VEGFR2 signaling axis, as we will describe below. Adult angiogenesis can also involve recruitment of circulating endothelial progenitors that become integrated in the vessel wall in a process known as adult vasculogenesis (Asahara et al. 1997, 1999).

In vertebrates, endothelial cells play the main roles in all the stages of the angiogenic process. Endothelial cells express the VEGF and the angiopoietin receptors that control the angiogenic process. Quiescent endothelial cells become activated by angiogenic signals (mainly VEGF as stated above, but also by other growth factors, cytokines and chemokines, see Muñoz-Chápuli et al., 2004 for a review), they alter the proteolytic balance and degradate basement membrane, they proliferate and migrate directionally towards the angiogenic stimulus and finally endothelial cells secrete a new basement membrane, recruit perivascular cells and reorganize to form a new, functional vessel.

Abbreviations used in this paper: VEGF, vascular endothelial growth factor; VEGFR, VEGF receptor

\footnotetext{
*Address correspondence to: Ramon Muñoz-Chápuli. Department of Animal Biology, Faculty of Science, University of Málaga, E-29071 Málaga, Spain. Fax: +34-952-131-668. e-mail: chapuli@uma.es
}

Final, author-corrected PDF published online: 24 June 2011.

ISSN: Online 1696-3547, Print 0214-6282 
This absolute prominence of endothelial cells in the angiogenesis of vertebrates raises the question about how the circulatory system (also called "hemal system" in these animals) grows in the invertebrate phyla, since hemal systems lack of true endothelial cells (Shigei et al., 2001; Muñoz-Chápuli et al., 2005; Muñoz-Chápuli and Pérez-Pomares, 2010). The vessels of most invertebrates ${ }^{1}$ consist of a network of spaces limited by the basement membranes of different kind of epithelia, mainly the endodermal epithelium of the gut, the coelomic epithelium or specialized myoepithelial cells from coelomic origin that can render part of these vessels contractile (Ruppert and Carle 1983; Ruppert 1997; for a review see Muñoz-Chápuli and Pérez-Pomares, 2010). This is called the Ruppert and Carle (R\&C) model since it was first described by

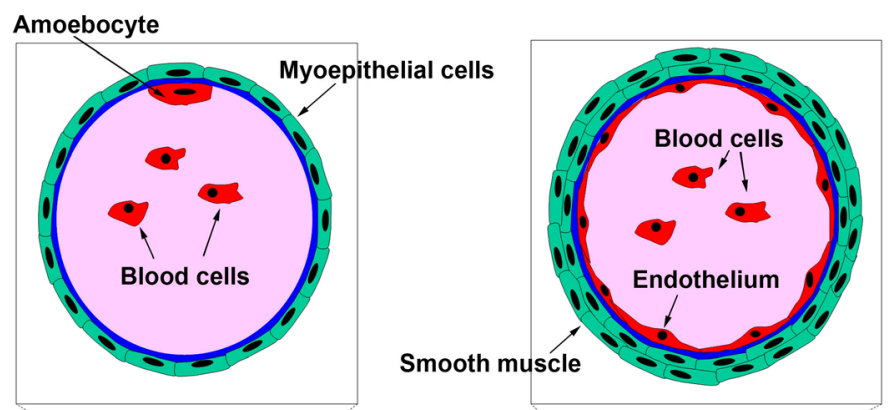

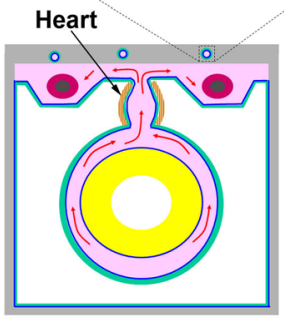

Hemal system

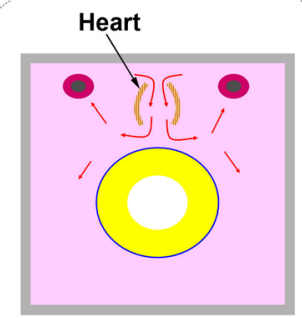

Hemocoelic system

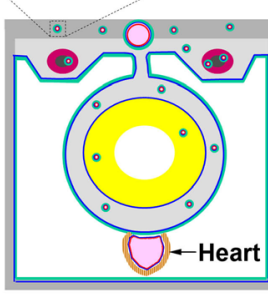

Endothelial C.S.
Fig. 1. Cartoon depicting three different types of circulatory system in metazoans (bottom) and the two basic vascular architectures found in this group (top). The circulatory spaces are shown in pink, coelomic epithelium, myoepithelial cells and smooth muscle in green, basement membranes in blue, viscera in purple, endoderm in yellow, heart in light brown and the body wall in grey. Hemal systems consist of spaces between the basement membranes of endodermal and mesodermal epithelia. The blood circulates between the digestive tract and the viscerae pumped by the heart, strategically located in the dorsal mesenterium. In large size species, microvessels appear in the body wall and in different organs. These microvessels are usually composed of a single layer of myoepithelial cells, with a luminal basement membrane. Amoebocytes (adhering blood cells) can be more or less abundant, and they appear attached to the basement membrane. Hemocoelic systems show an opening of the hemal system to the coelomic cavity, frequently associated to a disappearance of the coelomic epithelium. The blood freely circulates throughout the coelomic cavity. The endothelial circulatory system of vertebrates is fully composed of vessels constituted of a perivascular cell layer, probably derived from the ancestral myoepithelial cells, and an endothelial layer that probably derived from ancestral, amoebocyte-like cells through gaining of intercellular adhesions. For further details, see text and Muñoz-Chápuli et al. (2005). these authors (Ruppert and Carle 1983). In large invertebrates microvessels can be found within the tissues, but always with the same architecture consisting of myoepithelial cells with the basal surface (and the basement membrane) lining the vascular lumen (Figs. 1,2). The fact that the apical surface from the vertebrate endothelium is luminal while the endothelial basement membrane is abluminal has lead sometimes to the erroneous assumption that the invertebrate vessels are "inverted", i.e. that the basoapical polarity is reversed in vertebrates and invertebrates. Instead, we have proposed elsewhere (Muñoz-Chápuli et al., 2005; MuñozChápuli and Pérez-Pomares, 2010) that the basic difference between invertebrate and vertebrate vessels lies in the presence of an endothelial cell layer in the latter that does not exists in invertebrates (Figs. 1,2). In the vertebrate ancestors, an evolutionarily new epithelium lined the inner surface of the vessels formed by myoepithelial cells, forerunners of the vascular smooth muscle. Thus, there is no "inversion" of the basoapical polarity of the cells lining the vessel wall in vertebrates, but the appearance of a new cell layer whose polarity is inverse to that of the preexisting cells. We have also proposed that this evolutionary innovation of vertebrates can be explained if we assume that endothelial cells are evolutionary derivatives of some kind of invertebrate blood cells, through adhesion to the myoepithelial basement membranes and acquisition of epithelial features. In fact, amoebocytes (adherent blood cells) are frequently found attached to the inner vascular surface of many invertebrates (eg. cephalopods and annelids, see Fig. 2). Due to this localization, they have been frequently called "endothelial cells" (Casley-Smith, 1980). However, we think that the true endothelium should be defined by their epithelial features (basoapical polarity, intercellular junctions and anchoring to the basement membranes). Thus, free cells adhering to the myoepithelial basement membranes of the invertebrates cannot be considered as true endothelial cells, although probably these adhering cells can be regarded as similar to those that were the evolutionary ancestors of the vertebrate endothelium.

If endothelial cells, the main agents of the angiogenic process in vertebrates, are lacking in all the other metazoan phyla, how vascular growth occurs in invertebrates? Can we call "angiogenesis" to this process of vascular growth? We aim to summarize in this review the available knowledge about invertebrate angiogenesis, emphasizing what are the most important issues that remain still unknown. We will try also to clarify some potential misconceptions derived from a direct comparison of the processes of vascular growth in vertebrates and invertebrates, neglecting the differences in the cellular agents involved in both cases. Finally we will try to regard the vertebrate angiogenesis with an evolutionary perspective, analyzing how the signaling systems regulating the angiogenic process in vertebrates may have evolved.

\section{Vascular growth in invertebrates}

As stated above, the hemal system of invertebrates is composed of a network of spaces limited by basement membranes of endodermal, mesodermal and (occasionally) ectodermal epithelia. These spaces probably originated around the gut, between the

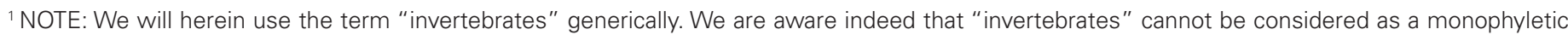

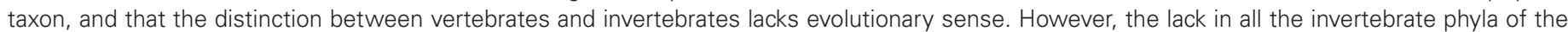
highly specialized features of the vertebrate circulatory system allows us to deal with them as a group. 


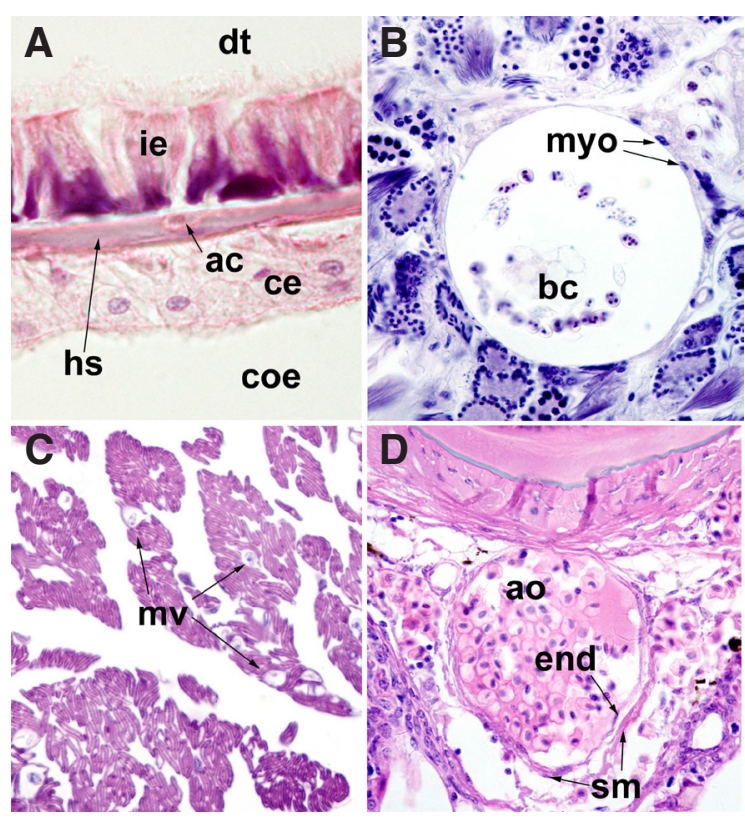

Fig. 2. Examples of hemal and endothelial circulatory systems. (A) Hemal system in the earthworm Lumbricus. The hemal space (hs) is located between the intestinal epithelium (ie) and the coelomic epithelium (ce). An amoebocyte (ac) appears attached to the basement membrane of the intestinal epithelium. Coe: coelomic cavity; dt: lumen of the digestive tract. (B) A visceral vessel in the gonad of the earthworm Lumbricus. The vessel wall is constituted by a single cell layer of myoepithelial cells (myo). Bc: blood cells. (C) Microvessels (mv) in the trunk muscle of the polychaete Nereis. These microvessels are also constituted by a single myoepithelial cell layer. Note the relative paucity of the microvessels as compared with the capillary network supplying the striated muscle of vertebrates. (D) Endothelial circulatory system in the phylogenetically most primitive vertebrates. In the dorsal aorta (ao) of the larva Ammocoetes of the lamprey (Petromyzon marinus) it is already present a double layer, an endothelium (end) and a smooth muscle cell layer (sm). The space existing between both layers is an artifact.

endodermal and the coelomic epithelia, allowing for an improved distribution of the nutrients absorbed by the intestine. The hemal fluid that fills the hemal cavities can be pumped between the gut and the viscera thanks to the contractile abilities developed by the coelomic epithelia and the myoepithelial cells derived from them, that are also responsible of the peristaltic movements of the digestive tract. It is important not to confound the hemal system with the hemocoelic cavities or the open lacunae of other animals, that can be derived of coelomic cavities or not, but they always lack of a lining constituted of cells or basement membranes (Fig. 1).

The body growth leads indeed to a corresponding enlargement of the hemal spaces, but the question is if there exists in the invertebrates a specific process of vascular growth that can invade avascular territories during development or to participate in tissue repair or remodelling in adults. There are surprisingly few reports in the literature about this issue. In fact, as far as we know, only three cases of vascular growth in adult invertebrates have been reported, in the colonial ascidian Botryllus schloesseri, the leech Hirudo medicinalis, and the squid Idiosepius paradoxus. In the first case, both, the normal growth of the extracorporeal vessels connecting the individuals from a colony and the regeneration of the circulatory system after injury have been described (Gasparini et al., 2007, 2008). In Hirudo, the development of some peculiar vascular-like structures was elicited by injury or by injection of VEGF or other growth factors (de Eguileor et al., 2001a,b; Tettamanti et al., 2003). In the squid, the expression of a VEGFR ortholog in developing blood vessels has been described (Yoshida et al., 2010). We will describe briefly these three processes in order to compare their features with the vertebrate angiogenesis.

Both, physiological as well as reparative growth of vessels have been described in a colonial urochordate, the ascidian Botryllus schlosseri. Urochordates constitute the phylogenetically closest lineage to the vertebrates, a fact that gives special relevance to these studies. However, individuals of Botryllus lack of an internal vascular system, except for a tubular heart constituted of a single layer of myoepithelial cells and a network of open sinuses and lacunae. These vascular spaces are interconnected in the colony by extracorporeal vessels derived from epidermal outgrowths, that exhibit the same basic architecture of the mioepithelial vessels, i.e. an epithelium with the apical surface abluminal and with the basement membrane lining the vascular lumen. When a new individual arises by asexual reproduction, it develops epidermal sprouts that connect their hemal cavities to the colony vessels (Gasparini et al., 2007, 2008). When the extracorporeal vessels and the common tunica are surgically removed, a new tunica is rapidly synthesized and new vessels are formed by sprouting of the preexisting ones. This process is dependent on VEGF/VEGFR signaling, as demonstrated by siRNA knockdown and pharmacological inhibition (Tiozzo et al., 2008).

The hirudineans or leeches are a group of carnivorous or bloodsuckling annelids. In the circulatory system of the acanthobdellid and rhynchobdellid hirudineans the hemal system coexists with an hemocoelomic system, a network of closed, interconnected cavities and tubes of coelomic origin (Fernández et al., 1992). However, the leech Hirudo medicinalis, an arhynchobdellid hirudinean, lack of blood vessels, and the circulatory system is thus limited to the hemocoelomic network of channels that does not penetrate in the muscular body wall. Around the epithelium of some of these channels there are large cells containing a brown pigment (the botryoidal tissue). This tissue, considered as a subtype of chloragogen cells, has a coelomic origin (Hartenstein, 2006). Botryoidal tissue can be stimulated by tissue injury or by injection of VEGF or FGF-2, giving rise to growing hollow channels, lined by endothelial-like cells, which allow cells from the immune system to arrive to the site of the stimulus (de Eguileor et al., 2001a,b; Tettamanti et al., 2003). This has been considered as an "angiogenic" process by these authors, who emphasize the similarity with processes of neovascularization of vertebrates, especially the response of botryoidal cells to the same activators of vertebrate angiogenesis (Tettamanti et al., 2003). However, the formation of channels by botryoidal cells seems to be related with defensive functions rather than with physiological body vascularization.

Cephalopods bear the most complex hemal system of all the invertebrates, a fact closely related with the large sizes attained by these animals, the largest ones among the invertebrates. The welldeveloped musculature of the cephalopods is supplied by a network of vessels of different calibers, but always with the same typical architecture of the invertebrates, myoepithelial cells with luminal basement membranes. Circulating cells are frequently adhered to these basement membranes. Their abundance in some vessels has lead to some authors to call them "endothelial cells", but as 
we have state above, the lack of epithelial features advises against the use of this term. Recently, the expression of a VEGFR ortholog in developing blood vessels of the squid Idiosepius paradoxus has been described (Yoshida et al., 2010). VEGFR-positive cells form sprouts and filopodia in peripheral blood vessels, suggesting invasion of tissues and organs such as the brain.

Significantly, in all these instances of invertebrate "angiogenesis", growth of vascular-like or vascular structures is elicited and apparently controlled by VEGF, a main angiogenic factor of vertebrates. However, in two cases, no endothelial cells are involved, since the vascular walls are either composed of coelomic-derived (Hirudo) or epidermal-derived (Botryllus) cells. In the case of the squid, that is probably the only report existing in the literature on physiological growth of vessels derived from the mesoderm, the authors do not show if the cells forming the sprouts and filopodia are myoepithelial or "endothelial-like" (i.e. circulating) cells. Thus, unless that in this last model can be demonstrated that the expression of the VEGFR and the invasive behaviour occurs in circulating cells (evolutionarily related to the vertebrate endothelium) and not in myoepithelial cells, the described processes of vascular growth in invertebrates would not be comparable, at the cellular level, with the vertebrate angiogenesis, since different cellular elements would be involved in both cases. Thus, we will compare the processes of vascular growth at the molecular level searching for a "deep homology" (in the sense of Shubin et al. 2009) underlying the cellular level and shared by all the processes of vascular growth in metazoans.

\section{Angiogenic signalling mechanisms in invertebrates}

Claims on the similarity between invertebrate and vertebrate angiogenesis lie on the sharing of signaling mechanisms, basically the involvement of VEGF and its receptor VEGFR. The family of endothelial growth factors in mammals is composed of VEGF-A, which is the physiologically most relevant factor, VEGF-B, VEGFC, VEGF-D, and the placental growth factor (PIGF) (Ferrara et al. 2003). Their biological effects are mainly performed by binding to the VEGFR2 receptor which is predominantly expressed by endothelial cells. VEGF-A also binds other receptors such as VEGFR1 and VEGFR3 (Breen, 2007). This variety of VEGFs and VEGFRs exhibited by vertebrates is most probably related with the double round of duplication of the whole vertebrate genome (Kasahara, 2007), but in invertebrates, and except for instances of specific gene duplication, such as the Drosophila PVF1-3 genes, we should expect single VEGFR and VEGF genes that would be orthologous to the vertebrate ones evolutionarily derived from them.

As stated above, VEGF stimulates the formation of the vascular channels in the leech Hirudo, its receptor is expressed in growing vessels of the squid Idiosepius and the requirement of the receptor VEGFR and its ligand VEGF in the sprouting of the epidermal-derived, extracorporeal vessels of Botryllus has been clearly substantiated (Tiozzo et al., 2008). This would suggest that a "deep homology" accounts for a common molecular regulation of the processes of vascular growth in all the metazoans bearing circulatory systems. However the VEGF/VEGFR system cannot be considered as specifically related to the circulatory system. These molecules are involved in multiple processes of cellular signaling, in most cases related with directional migration. For example, VEGF/VEGFR regulate growth of the endodermal gastrovascular channels in the jellyfish Podocoryne carnea (Seipel et al., 2004). The same system regulates migration and differentiation of the skeletogenic primary mesenchymal cells of the sea urchin (Duloquin etal., 2007). VER1-4, the tyrosine-kinase receptors of PVF-1 (a probable ortholog of VEGF/ PDGF) in Caenorhabditis, are expressed in neural cells (Popovici et al., 2002). The high degree of conservation of these molecules allows PVF-1 to activate the human VEGF receptor 1 and 2, and to be angiogenic in two models of vertebrates (Tarsitano et al., 2006). PVR, a probable VEGFR/PDGFR ortholog, is expressed in Drosophila hemocytes, that migrate in response to VEGF signals, but also in follicular border cells, that are guided by these signals towards the oocyte (Duchek et al., 2001) and in salivary glands, whose position is regulated by this system (Harris et al., 2007). Even in vertebrates, VEGF/VEGFR is not an endothelial-restricted signaling system, since VEGF is involved in glial, neural and neural crest cell migration (Wittko et al., 2009; Kranich et al., 2009; Mani et al., 2010; MacLennan et al., 2010; for a review see Senger, 2010).

Another important issue is the regulation of the VEGF expression. In vertebrate angiogenesis it is well known that the main activator of the expression of VEGF-A is tissue hypoxia, through stabilization of the hypoxia-inducible factor $\alpha(\mathrm{HIF} \alpha)$ that is rapidly degraded in normal conditions of oxygenation but it is stabilized in hypoxic conditions, translocating to the nucleus, binding some cofactors and transactivating expression of the VEGF-A gene among others. However, it is doubtful that regulation of the VEGF gene in invertebrates occurs by a similar mechanisms. Just to quote two examples, the Drosophila VEGF/PDGF genes, called PVF1-3, are broadly expressed in many tissues, inducing in this way the migration of blood cells throughout the body. In Botryllus, where VEGF and VEGFR seem to be expressed in the growing extracorporal vessels (Gasparini et al., 2007, 2008), it seems highly unlikely that hypoxia exists in the surface of the colony, very close to the oxygenated seawater that surrounds the tunica. Furthermore, the overlapping expression pattern of VEGF and VEGFR in this species is different to the usual expression patterns of these proteins that normally do not coincide. However, it is surprising the high similarity between the regulation of the VEGF-A and the FGF genes in vertebrate angiogenesis and in development of the tracheal system in Drosophila, respectively. We will discuss this similarity below.

Other signalling systems closely related with vertebrate angiogenesis have not been identified in invertebrate vascular growth, emphasizing in this way the differences between these processes also at the molecular level. For example, angiopoietins regulate vascular stability in vertebrates. This family includes four proteins (Angiopoietin-1-4), that are ligands of two tyrosine kinase receptors (Tie1 and Tie2). Ang-1 activates Tie2 signalling promoting vessel assembly and stabilization by facilitating recruitment and high association with mural cells and mediating survival signals for endothelial cells (Thomas and Augustin, 2009). Ang-1 is expressed and secreted by perivascular cells (Sundberg et al. 2002). On the contrary, Ang-2, produced by endothelial cells, is only expressed in areas of vascular remodelling and inhibits the Ang-1 mediated Tie2 activation. The endothelium is maintained in a quiescent state by Ang-1, but localised expression of Ang-2 allows vascular remodelling and makes endothelial cells accessible to the VEGF angiogenic stimulus (Jones et al., 2001). In the absence of the mitogenic and survival signals from VEGF, however, endothelial cells are more likely to undergo apoptosis, leading to vessel regression (Plank et al., 2004).

There are virtually no data in the literature about angiopoietins 
and Tie receptors in invertebrates. Proteins with sequence similarity to angiopoietins have been reported by Dormer and Beck (2005) in Caenorhabditis, Drosophilaand Anophelesthrough in silico search, but their orthology with the vertebrate angiopoietins is unclear. Putative Tie orthologs have been described in the sea urchin (Bradham et al., 2006), Ciona (Shiu and Li, 2004) and Branchiostoma (D'Aniello et al., 2008), but their functions or site of expression remain unknown. These sequences significantly cluster with vertebrate Tie sequences in a molecular phylogeny analysis (Chicón, 2008).

\section{Does angiogenesis exist in invertebrates?}

We think that profound differences exist between the processes of vascular growth in vertebrates and invertebrates. From the cellular point of view, the existence in the vertebrate vessels of an endothelium, an unique cell layer in the metazoan circulatory system, confers exclusive features to the angiogenic process, performed along all their stages by the endothelial cells. In invertebrates there are few data about the vascular growth at the cellular level, although the prominence of myoepithelial cells forming the walls of the small caliber vessels suggests that these cells are responsible of the invasion of avascular tissues. The precise mechanism remains unknown, but we can speculate about the possibility of the formation of new hemal spaces between multilayered myoepithelial cells. Two mechanisms can be envisaged for this process, since both have already been described in invertebrates in relation to the opening of vascular spaces. First, the degradation of basal extracellular matrix between two epithelial sheets by macrophage-like cells allows for the expansion of hemal spaces in amphioxus, as described by Kucera et al. (2009). On the other hand, the opening of a lumen between the cardiac tube cells of Drosophila occurs by localized inhibition of cell adhesion mediated by Slit and Robo, two main mediators of cell repulsion (Santiago-Martinez et al., 2008; Medioni et al., 2008). It is important to remark that myoepithelial vessel growth by these mechanisms would involve no degradation of the vascular basement membranes, contrarily to what happens in vertebrate angiogenesis. This difference had been already noted by Gasparini et al., 2007) in their report on the growth of the ectodermal vessels of Botryllus.

From the molecular point of view it is clear that the VEGF/ VEGFR system seem to be involved in vascular growth of both, vertebrates and invertebrates. However, it is also true that this signaling system is involved in many processes of directed migration, and their regulation is probably different in vertebrate angiogenesis and invertebrate vascular growth. Thus, the VEGFNEGFR axis cannot be considered as a hallmark of the vascular growth in the metazoans. For these reasons, and considering that a restriction of the term "angiogenesis" only to vertebrates could be unjustified, we suggest to call "endothelial angiogenesis" to the vertebrate angiogenic process when it should be compared with the invertebrate process of vascular growth, while "non-endothelial angiogenesis" or, if further findings supports this, "myoepithelial angiogenesis" could be the most suitable term for the process of vascular growth in invertebrates.

\section{Endothelial angiogenesis - an evolutionary perpsective}

Endothelial angiogenesis is a process of vascular growth exclusive of vertebrates because its main agent, the endothelium, constitutes an evolutionary innovation of this taxon. Endothelial cells use VEGF as the main angiogenic signal, the same factor involved in blood cell migration by some invertebrates, such as Drosophila. This is not surprising when we consider the evolutionary origin of the endothelium from ancestral blood cells. In fact, as we have stated elsewhere (Muñoz-Chápuli et al., 2005), we could regard endothelial angiogenesis as a transient reacquisition of the ancestral, motile, invasive phenotype of some blood cells by the normally quiescent endothelial cells. The advantages of endothelial angiogenesis for vertebrate evolution are outstanding. Thanks to the endothelial lining, immune cells are recruited to sites of infection. The interplay of endothelial and perivascular cells allows for a fine control of blood flow. And importantly, the highly efficient mechanism of vascular growth mediated by endothelial cells led to vertebrates not only to attain the largest sizes of the Animal Kingdom, but also to greatly expand their somatic compartments (head, trunk muscle, limbs and tail).

Tubular growth and branching morphogenesis are processes involved in the formation of multiple tissues and organs. Despite superficial similarities between these processes, different molecular mechanisms can be used for the same purposes in different organs and taxa. When we consider the whole process of endothelial angiogenesis, it is surprising the number of common molecular

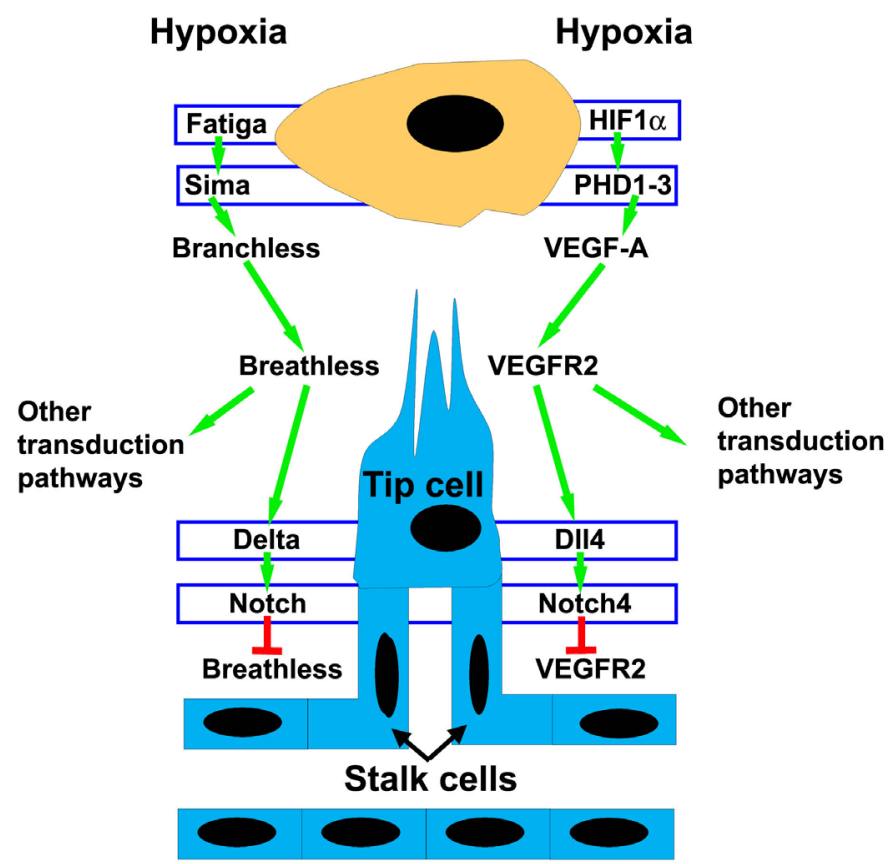

\section{Tracheogenesis in Drosophila}

\section{Endothelial angiogenesis in vertebrates}

Fig. 3. Simplified sketch for a comparison of the molecular interactions regulating tracheal development in Drosophila (left) and endothelial angiogenesis in vertebrates (right). The hypoxic inducer tissue is represented by the orange cell. Green and red lines indicate activation and inhibition, respectively. Putative orthologous genes are enclosed in blue rectangles. Both pathways are basically identical, except for the replacement of branchless and breathless (the Drosophila orthologous of FGF and FGFR, respectively) by VEGF-A and VEGFR2. The detailed interactions are explained in the text. 
pathways shared with the formation of the tracheal system in insects (Horowitz and Simons, 2008) (Fig. 3). In both cases the initial stimulus is hypoxia, sensed by prolyl hydroxylases (fatiga in Drosophila and the HIF prolyl hydroxylases PHD1-3 in vertebrates) that hydroxyle the hypoxia-inducible factors (HIF), stabilizing them and avoiding their degradation. The main difference between both pathways is that sima (the HIF homologue from Drosophila) activates branchless expression (an FGF homologue), while the vertebrate HIF1 $\alpha$ activates VEGF-A expression. Both growth factors bind to their tyrosine kinase receptors (breathless in Drosophila, VEGFR2 in vertebrates) on the leading cells of the sprouts, called the "tip" cells, that are developing filopodia towards the stimulus. Later, the pathways become again similar in both models. Signals derived from the tyrosine kinase receptors activate a number of transduction pathways (eg. MAPK) and induce the expressíon of Notch ligands (Delta in Drosophila, DII4 in vertebrates) in the tip cells. These ligands activate Notch signalling in the neighbouring cells (called the "stalk cells") leading to the repression of breathless or VEGFR2, and thus to a decreased responsivity to the tracheogenic/angiogenic stimuli. This mechanism regulates the process at a single cell level.

The similarity between both mechanisms is so appealing that suggests that an evolutionarily conserved network of gene regulation related with the response to hypoxia (probably a "kernel" in the sense given to this expression by Hinman and Davidson, 2007) was recruited by the early endothelial cells of vertebrates to regulate vascular growth in response to hypoxia. The only innovation was the substitution of branchless/breathless by VEGF-A/VEGFR2, not surprisingly given the use of this signaling system by invertebrate hemocytes, evolutionary ancestors of the endothelial cells. It is unknown if this "kernel" is functional in any model of invertebrate vascular growth, despite the use of VEGF signals by them. Further refining of the control of the endothelial angiogenesis was probably achieved by a second regulatory layer mediated by the signaling system angiopoietins/Tie receptors and related with the interplay exclusively established in vertebrates between endothelial and perivascular cells.

\section{Concluding remarks - issues for the future}

From the preceding data we can conclude that there is much work to do in the field of the invertebrate vascular growth, especially when we avoid an oversimplification of the cellular and molecular mechanisms involved in this process. We still do not know the origin and nature of the cellular agents of the invertebrate vascular growth. We ignore the role played by hypoxia in the vascularization of the tissues of invertebrates. We do not know how the VEGF/ VEGFR expression that appears associated with invertebrate vascular growth is regulated, what transduction pathways are activated when VEGF binds to VEGFR, what role (if any) is played by angiopoietins and Tie receptors, and if Notch is controling the process of vascular growth of invertebrates at the single cell scale as occurs during the endothelial angiogenesis of the vertebrates and the tracheal development of the insects. We do not know what are the cues guiding vascular growth in invertebrates, and if there is a neurovascular link involving semaphorins, slit, netrins and their receptors, as it has been described in vertebrates (Larrivée et al., 2009).

We have the feeling that future research on these issues will lead to findings that will emphasize more the differences than the similarities between the processes of invertebrate vascular growth and endothelial angiogenesis. In this case, we will need to be very cautious about the possibilities of using invertebrates animals as models for the study of endothelial angiogenesis.

\section{Acknowledgements}

This work was supported by grants BFU2008-02384 and BFU2009-07929 (Ministerio de Ciencia e Innovación), RD06/0010/0015 (TerCel network, ISCIII), RD96/0014/1009 (RECAVAnetwork, ISCIII), P08-CTS-03618 (Junta de Andalucia) and LSHM-CT-2005-018630 (VI framework, UE). We would like to express our thanks for valuable comments and suggestions to Dr. Masa-aki Yoshida, Ochanomizu University, Tokyo.

\section{References}

ASAHARA, T., MASUDA, H., TAKAHASHI, T., KALKA, C., PASTORE, C., SILVER M., KEARNE, M., MAGNER, M. and ISNER, J.M. (1999). Bone marrow origin of endothelial progenitor cells responsible for postnatal vasculogenesis in physiological and pathological neovascularization. Circ. Res. 85: 221-228.

ASAHARA, T., MUROHARA, T., SULLIVAN, A., SILVER, M., VAN DER ZEE R., LI, T., WITZENBICHLER, B., SCHATTEMAN, G. and ISNER, J.M. (1997). Isolation of putative progenitor endothelial cells for angiogenesis. Science 275: 964-967.

BRADHAM, C.A., FOLTZ, K.R., BEANE, W.S., ARNONE, M.I., RIZZO, F., COFFMAN J.A., MUSHEGIAN, A., GOEL, M., MORALES, J., GENEVIERE, A.M., LAPRAZ, F., ROBERTSON, A.J., KELKAR, H., LOZA-COLL, M., TOWNLEY, I.K., RAISCH, M., ROUX, M.M., LEPAGE, T., GACHE, C., MCCLAY, D.R. and MANNING G. (2006). The sea urchin kinome: a first look. Dev. Biol. 300: 180-193.

BREEN, E.C. (2007). VEGF in biological control. J. Cell Biochem. 102: 1358-1367. CARMELIETP. (2005). Angiogenesis in life, disease and medicine. Nature438: 932-936

CASLEY-SMITH, J. R. (1980). Comparative fine structure of the microvasculature and endothelium. In: Vascular endothelium and basement membranes (Eds. Altura B. M., Davis, E. and Harder, H.) Karger, Basel, pp. 1-44.

CHICÓN, C. (2008). Filogenia molecular de VEGFR2 y otros receptores tirosina quinasa relacionados con el endotelio vascular. MSci. thesis, Universidad Internacional de Andalucía.

D'ANIELLO, S. IRIMIA, M., MAESO, I., PASCUAL-ANAYA, J., JIMÉNEZ-DELGADO, S., BERTRAND, S. and JORDI GARCIA-FERNÁNDEZ (2008). Gene expansion and retention leads to a diverse tyrosine kinase superfamily in amphioxus. Mol. Biol. Evol. 25: 1841-1854.

DE EGUILEOR, M., GRIMALDI, A., TETTAMANTI, G., CONGIU, T., PROTASONI, M., REGUZZONI, M., VALVASSORI, R. and LANZAVECCHIAG. (2001). Ultrastructure and functional versatility of hirudinean botryoidal tissue. Tissue Cell. 33: 332-341.

DE EGUILEOR, M., GRIMALDI, A., TETTAMANTI, G., FERRARESE, R., CONGIU, T., PROTASONI, M., PERLETTI, G., VALVASSORI, R. and LANZAVECCHIA G. (2001). Hirudo medicinalis: a new model for testing activators and inhibitors of angiogenesis. Angiogenesis 4: 299-312.

DORMER, A. and BECK, G. (2005). Evolutionary analysis of human vascular endothelial growth factor, angiopoietin and tyrosine endothelial kinase involved in angiogenesis and immunity. In Silico Biol. 5: 323-339.

DUCHEK, P., SOMOGYI, K., JÉKELY, G., BECCARI, S., and RØRTH, P. (2001). Guidance of cell migration by the Drosophila PDGF/VEGF receptor. Cell 107: 17-26.

DULOQUIN, L., LHOMOND, G. and GACHE C. (2007). Localized VEGF signaling from ectoderm to mesenchyme cells controls morphogenesis of the sea urchin embryo skeleton. Development 134: 2293-2302.

FERNÁNDEZ, J., TÉLLEZ, V. and OLEA, N. (1992). Hirudinea. In: Microscopic Anatomy of Invertebrates. Vol. 7: Annelida. (Eds. Harrison, F.W. and Chia, F.S.). Wiley-Liss, New York, pp. 323-393.

FERRARA, N., GERBER H.P. and LECOUTER, J. (2003). The biology of VEGF and its receptors. Nat. Med. 9: 669-676.

GASPARINI, F., BURIGHEL, P., MANNI, L. and ZANIOLO, G. (2008).h Vascular regeneration and angiogenic-like sprouting mechanism in a compound ascidian is similar to vertebrates. Evol. Dev. 10: 591-605.

GASPARINI, F., LONGO, F., MANNI, L., BURIGHEL, P. and ZANIOLO, G. (2007) 
Tubular sprouting as a mode of vascular formation in a colonial ascidian (Tunicata). Dev. Dyn. 236: 719-731.

HARRIS, K.E., SCHNITTKE, N. and BECKENDORF, S.K.(2007). Two ligands signal through the Drosophila PDGF/VEGF receptor to ensure proper salivary gland positioning. Mech. Dev. 124: 441-448.

HARTENSTEIN, V. (2006). Blood cells and blood cell development in the animal kingdom. Annu. Rev. Cell Dev. Biol. 22: 677-712.

HINMAN, V.F. and DAVIDSON, E.H. (2007). Evolutionary plasticity of developmental gene regulatory network architecture. Proc. Natl. Acad. Sci. USA 104: 19404-19409.

HOROWITZ, A. and SIMONS, M. (2008). Branching morphogenesis. Circ. Res. 103: 784-795.

JONES, N., ILJIN, K., DUMONT, D.J. and ALITALO, K. (2001). Tie receptors: new modulators of angiogenic and lymphangiogenic responses. Nat. Rev. Mol. Cell Biol. 2: 257-267.

KASAHARA M. (2007). The 2R hypothesis: an update. Curr. Opin. Immunol. 19: 547-552.

KRANICH, S., HATTERMANN, K., SPECHT, A., LUCIUS, R. and MENTLEIN, R. (2009). VEGFR-3/FIt-4 mediates proliferation and chemotaxis in glial precursor cells. Neurochem. Int. 55:747-753.

KUCERA, T., STRILI, B., REGENER, K., SCHUBERT, M., LAUDET, V. and LAMMERT, E. (2009). Ancestral vascular lumen formation via basal cell surfaces. PLoS One. 4: e4132.

LARRIVÉE, B., FREITAS, C., SUCHTING, S., BRUNET, I. and EICHMANN, A. (2009). Guidance of vascular development: lessons from the nervous system. Circ. Res. 104: 428-441.

MANI, N., KHAIBULLINA, A., KRUM, J.M. and ROSENSTEIN, J.M. (2010). Vascular endothelial growth factor enhances migration of astroglial cells in subventricular zone neurosphere cultures. J. Neurosci. Res. 88: 248-257.

MCLENNAN, R., TEDDY, J.M., KASEMEIER-KULESA, J.C., ROMINE, M.H. and KULESA, P.M. (2010). Vascular endothelial growth factor (VEGF) regulates cranial neural crest migration in vivo. Dev. Biol. 339: 114-125.

MEDIONI, C., ASTIER, M., ZMOJDZIAN, M., JAGLA, K., SÉMÉRIVA, M. (2008). Genetic control of cell morphogenesis during Drosophila Melanogaster cardiac tube formation. J. Cell Biol. 182: 249-261.

MUÑOZ-CHÁPULI R., CARMONA, R., GUADIX, J.A., MACÍAS, D. and PÉREZPOMARES, J.M. (2005). The origin of the endothelial cells: an evo-devo approach for the invertebrate/vertebrate transition of the circulatory system. Evol. Dev. 7: 351-358.

MUÑOZ-CHÁPULI, R. and PÉREZ-POMARES, J.M. (2010). Origin of the vertebrate endothelial cell lineage: ontogeny and phylogeny. In: Heartdevelopment and regeneration (Eds. Rosenthal, N. and Harvey, R.P.), Elsevier, Amsterdam, pp. 465-486.

MUÑOZ-CHÁPULI, R., QUESADA, A.R. and MEDINA. M.A. (2004). Angiogenesis and signal transduction in endothelial cells. Cell. Mol. Life Sci. 61: 2224-2243.

PLANK, M.J., SLEEMAN, B.D. and JONES, P.F. (2004). The role of the angiopoietins in tumour angiogenesis. Growth Factors 22: 1-11.

POPOVICI, C., ISNARDON, D., BIRNBAUM, D. and ROUBIN R. (2002). Caenorhabditis elegans receptors related to mammalian vascular endothelial growth factor receptors are expressed in neural cells. Neurosci. Lett. 329: 116-120.

RUPPERT, E.E. (1997). Cephalochordata (Acrania). In: Microscopic Anatomy of Invertebrates. Vol. 15: Hemichordata, Chaetognatha and the Invertebrate Chordates (Eds. Harrison, F.W. and Ruppert, E.E.), Wiley-Liss, New York, pp. 349-504.

RUPPERT, E.E. and CARLE, K.J. (1983). Morphology of the metazoan circulatory systems. Zoomorphology 103: 193-208.

SANTIAGO-MARTÍNEZ, E., SOPLOP, N.H., PATEL, R. and KRAMER, S.G. (2008). Repulsion by Slit and Roundabout prevents Shotgun/E-cadherin-mediated cell adhesion during Drosophila heart tube lumen formation. J. Cell Biol. 182: 241-248.

SEIPEL, K., EBERHARDT, M., MÜLLER, P., PESCIA, E., YANZE, N. and SCHMID, V. (2004). Homologs of vascular endothelial growth factor and receptor, VEGF and VEGFR, in the jellyfish Podocoryne carnea. Dev. Dyn. 231: 303-312.

SEMENZA, G.L. (2007). Vasculogenesis, angiogenesis and arteriogenesis: mechanisms of blood vessel formation and remodeling. J. Cell Biochem. 102: 840-847.

SENGER, D.R. (2010). Vascular endothelial growth factor: much more than an angiogenesis factor. Mol. Biol. Cell. 21: 377-379.

SHIGEI, T., TSURU, H., ISHIKAWA, N. and YOSHIOKA, K. (2001). Absence of endothelium in invertebrate blood vessels: significance of endothelium and sympathetic nerve/medial smooth muscle in the vertebrate vascular system. Jpn. J. Pharmacol. 87: 253-260.

SHIU, S-H. and LI, W-H. (2004). Origins, lineage-specific expansions and multiple losses of tyrosine kinases in eukaryotes. Mol. Biol. Evol. 21: 828-840.

SHUBIN, N., TABIN, C. and CARROLL, S. (2009). Deep homology and the origins of evolutionary novelty. Nature $457: 818-823$.

SUNDBERG, C., KOWANETZ, M., BROWN, L.F., DETMAR, M. and DVORAK. H.F. Stable expression of angiopoietin-1 and other markers by cultured pericytes: phenotypic similarities to a subpopulation of cells in maturing vessels during later stages of angiogenesis in vivo. Lab. Invest. 82: 387-401.

TARSITANO, M., DE FALCO, S., COLONNA, V., MCGHEE, J.D. and PERSICO, M.G. (2006). The $C$. elegans pvf-1 gene encodes a PDGF/VEGF-like factor able to bind mammalian VEGF receptors and to induce angiogenesis. FASEB J. 20:227-233

TETTAMANTI, G., GRIMALDI, A., VALVASSORI, R., RINALDI, L. and DE EGUILEOR, M. (2003). Vascular endothelial growth factor is involved in neoangiogenesis in Hirudo medicinalis (Annelida, Hirudinea). Cytokine 22: 168-179.

THOMAS, M., and AUGUSTIN, H.G. (2009). The role of the Angiopoietins in vascular morphogenesis. Angiogenesis 12: 125-137.

TIOZZO, S., VOSKOBOYNIK, A., BROWN, F.D. and DE TOMASO, A.W. (2008). A conserved role of the VEGF pathway in angiogenesis of an ectodermally-derived vasculature. Dev. Biol. 315: 243-255.

WITTKO, I.M., SCHÄNZER, A., KUZMICHEV, A., SCHNEIDER, F.T., SHIBUYA, M., RAAB, S. and PLATE, K.H. (2009). VEGFR-1 regulates adult olfactory bulb neurogenesis and migration of neural progenitors in the rostral migratory stream in vivo. J. Neurosci. 29: 8704-8714.

YOSHIDA, M.A., SHIGENO, S., TSUNEKI, K. and FURUYA, H. (2010). Squid vascular endothelial growth factor receptor: a shared molecular signature in the convergent evolution of closed circulatory systems. Evol. Dev. 12: 25-33. 


\section{Further Related Reading, published previously in the Int. J. Dev. Biol.}

The seminal work of Werner Risau in the study of the development of the vascular system Domenico Ribatti

Int. J. Dev. Biol. (2010) 54: 567-572

Embryonic development of the proepicardium and coronary vessels Anna Ratajska, Elzbieta Czarnowska and Bogdan Ciszek

Int. J. Dev. Biol. (2008) 52: 229-236

Vasculogenesis and angiogenesis in the mouse embryo studied using quail/mouse chimeras Michel Pudliszewski and Luc Pardanaud

Int. J. Dev. Biol. (2005) 49: 355-361

Vascular development: from precursor cells to branched arterial and venous networks Anne Eichmann, Li Yuan, Delphine Moyon, Ferdinand leNoble, Luc Pardanaud and Christiane Bréant Int. J. Dev. Biol. (2005) 49: 259-267

Parallels in invasion and angiogenesis provide pivotal points for therapeutic intervention Suzanne A. Eccles

Int. J. Dev. Biol. (2004) 48: 583-598

5 yr ISI Impact Factor $(2009)=3.253$

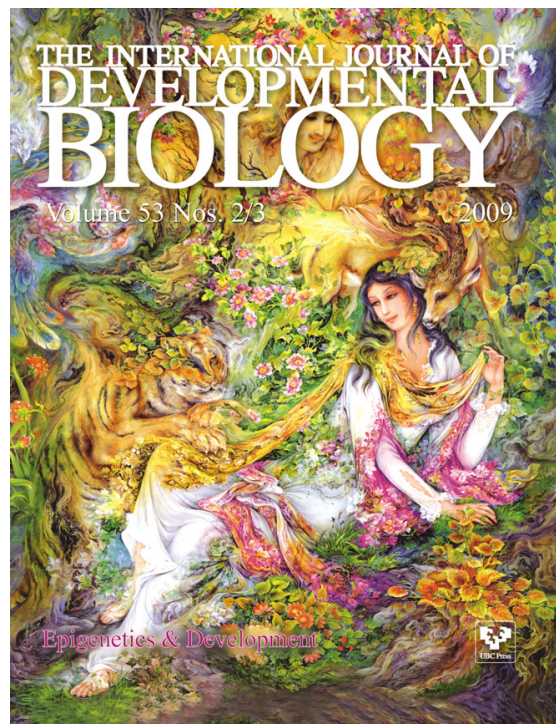

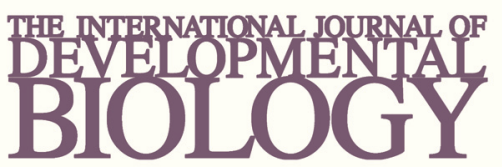

Volume 54 Nos. 6/7
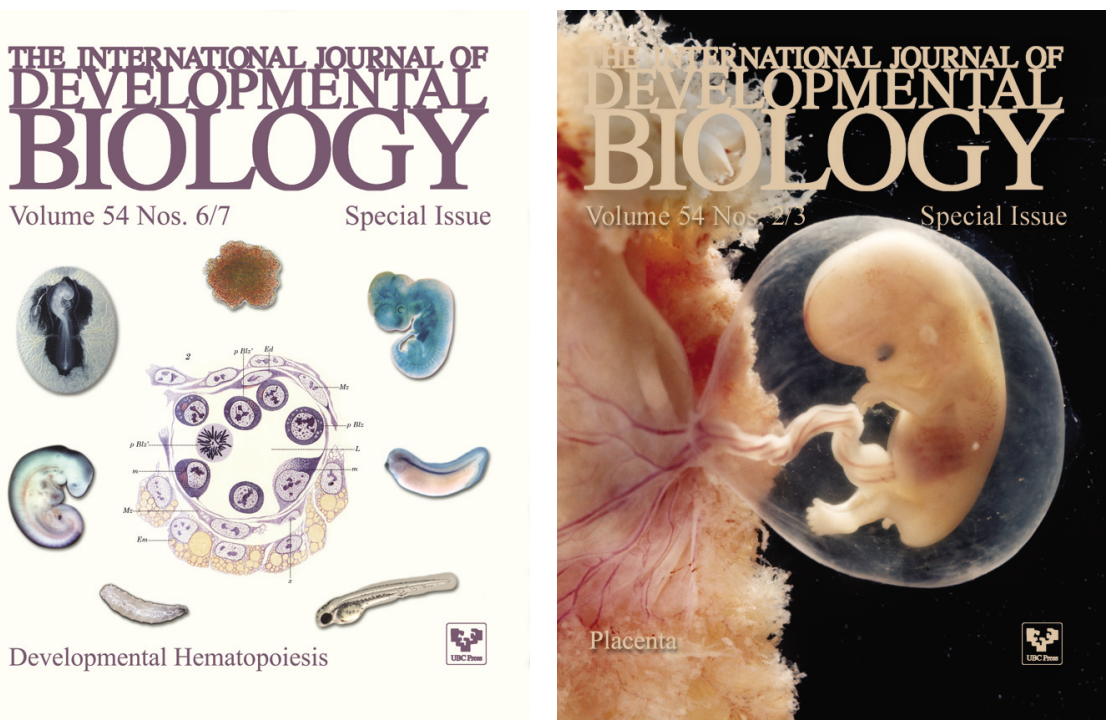